\title{
DETECTION OF OIL POLLUTION HOTSPOTS AND LEAK SOURCES THROUGH THE QUANTITATIVE ASSESSMENT OF THE PERSISTENCE AND TEMPORAL REPETITION OF REGULAR OIL SPILLS IN THE CASPIAN SEA USING REMOTE SENSING AND GIS
}

\author{
E. R. Bayramov ${ }^{\text {a, } *, \text { M. F. Buchroithner }}{ }^{\text {a }}$, R. V. Bayramov ${ }^{b}$ \\ ${ }^{a}$ Institute for Cartography, Dresden University of Technology, Dresden, Germany. \\ emil.bayramov@yahoo.com; manfred.buchroithner@tu-dresden.de \\ b Baku State University, Faculty of Geography, Baku, Azerbaijan - rafael_karta@mail.ru
}

Commission VIII, WG III/

KEY WORDS: SAR, ENVISAT, Oil Rocks

\begin{abstract}
:
The main goal of this research was to detect oil spills, to determine the oil spill frequencies and to approximate oil leak sources around the Oil Rocks Settlement, the Chilov and Pirallahi Islands in the Caspian Sea using 136 multi-temporal ENVISAT Advanced Synthetic Aperture Radar Wide Swath Medium Resolution Images acquired during 2006-2010.

The following oil spill frequencies were observed around the Oil Rocks Settlement, the Chilov and Pirallahi Islands: 2-10 (3471.04 sq. km.), 11-20 (971.66 sq. km.), 21-50 (692.44 sq. km.), 51-128 (191.38 sq. km.). The most critical oil leak sources with the frequency range of 41-128 were observed at the Oil Rocks Settlement. The exponential regression analysis between wind speeds and oil slick areas detected from 136 multi-temporal ENVISAT images revealed the regression coefficient equal to 63\%. The regression model showed that larger oil spill areas were observed with decreasing wind speeds. The spatiotemporal patterns of currents in the Caspian Sea explained the multi-directional spatial distribution of oil spills around Oil Rocks Settlement, the Chilov and Pirallahi Islands. The linear regression analysis between detected oil spill frequencies and predicted oil contamination probability by the stochastic model showed the positive trend with the regression coefficient of $30 \%$.
\end{abstract}

\section{INTRODUCTION}

The Oil Rocks Settlement, Chilov and Pirallahi Islands in the Caspian Sea were selected as the study areas because of their long-term oil exploration history. It is well known that microwave sensors have the advantage for oil slick monitoring due to its wide area coverage and day and night capabilities (Akar et al. 2011; Martinez et al. 1996; Ziemke 1996; Kubat et al. 1998; Del Frate et al. 2000; Topouzelis et al. 2002; Topouzelis et al. 2007). Radar backscattering level decreases with slick and appears as a dark patch with lower backscatter from the sea surface (Girard-Ardhuin et al. 2003). The limitation of synthetic-aperture radar (SAR) is that it does not have capabilities for oil spill thickness estimation and oil type recognition. However, SAR is useful particularly for searching large areas and observing oceans and seas at night and at cloudy weather conditions.

Possibilities for the detection of oil slicks depend on radar polarization modes, height of the waves, the amount of oil that has been released, slick nature, the speed of the wind and type of oil (Espedal et al. 1999; Espedal 1998; Girard-Ardhuin et al. 2003; O'Brein et al. 2005; Kotova et al. 1998; Gade et al. 2000).

The discrimination of oil slicks from oil spill look-alikes produced by oceanic and atmospheric processes is one of the most complex issues in the process of oil slick detection from SAR images. Discrimination of oil slicks from look-alikes is performed based on the textural, geometrical, radiometric, persistence and temporal repetition (Akar et al. 2011; Brekke et al. 2005; Karantzalos et al. 2008; Topouzelis 2008; Solberg et al. 1999).

The main goal of this research was to study oil pollution around the Oil Rocks Settlement, Chilov and Pirallahi Islands in the Caspian Sea using ENVISAT Advanced Synthetic Aperture Radar (ASAR) Wide Swath Medium Resolution satellite images acquired during the period of 2006-2010. The detailed research goals are following:

1. Detection of oil spills around the Oil Rocks Settlement, Chilov and Pirallahi Islands in the Caspian Sea using 136 multitemporal ENVISAT SAR images acquired for the period of 2006-2010

2. Computation of oil spill frequencies based on detected oil spills from 136 multi-temporal ENVISAT SAR images for the determination of spatiotemporal distribution trends of oil spills and hot spots with persistence and temporal repetition of regular oil pollution in marine environment

3. Approximation of probable oil leak sources at the Oil Rocks Settlement and around Chilov and Pirallahi Islands based on the frequencies of detected oil pollution

4. Determination of spatial relationships among areas of detected oil spills, wind speeds and currents in the Caspian Sea 5. Cross-validation of the achieved results using computed oil spill frequencies from multi-temporal ENVISAT SAR images and predicted contamination probability using stochastic oil spill modelling in OSCAR software.

\footnotetext{
* Corresponding author
} 


\section{STUDY AREA}

The Oil Rocks Settlement, Chilov and Pirallahi Islands in the Caspian Sea were selected as the research areas because of their long-term oil exploration history. The difference is that the Oil Rocks Settlement is artificially developed one whereas Chilov and Pirallahi Islands have the natural origin. The Oil Rocks is an industrial settlement in Baku, Azerbaijan. It is located $35 \mathrm{~km}$ from the coast of the Caspian Sea. The Oil Rocks is a functional city with a population of about 2,000 and with a length from east to west over $300 \mathrm{~km}$. The map of the Oil Rocks Settlement, Chilov and Pirallahi Islands is presented in Figure 1. The settlement of the Oil Rocks was built in 1949 after oil was discovered there at 1100 meters beneath the Caspian Sea and it became the first offshore oil infrastructure based on the steel trestle bridges joining the man-made islands in Azerbaijan (Figure 2a). By 1951, the Oil Rocks Settlement was ready for production with the equipped infrastructure needed at the time. In 1952, the systematic construction of trestle bridges connecting the artificial islands was begun. Chilov Island is located $16 \mathrm{~km}$ from the coast of the Caspian Sea. Pirallahi Island is located $1.6 \mathrm{~km}$ from the coast of the Caspian Sea (Figure 2b). Oil deposits on the northern part of Pirallahi Island are estimated at 1.2 million tons.

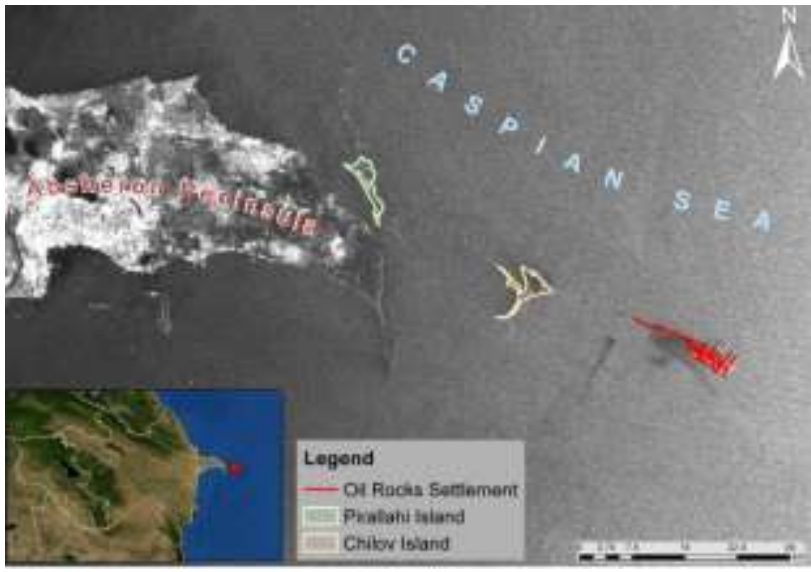

Figure 1. Map of the Oil Rocks Settlement, Pirallahi \& Chilov Islands
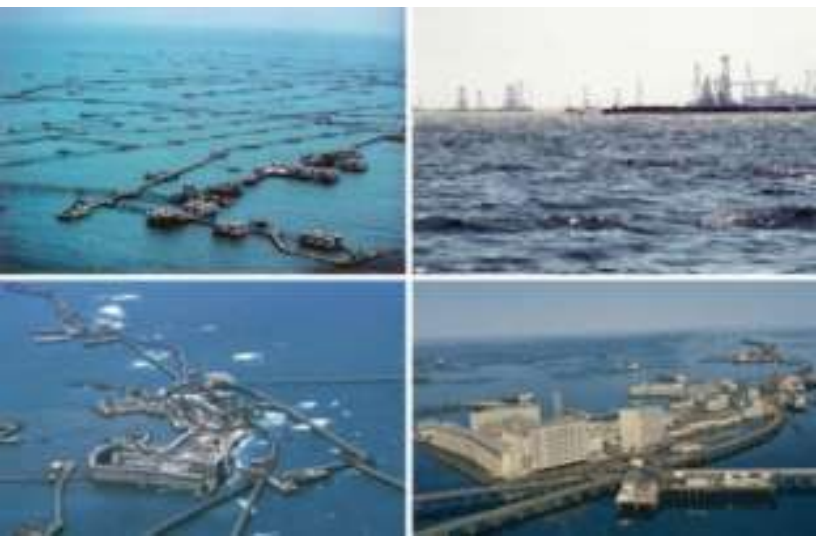

Figure 2. (a) Picture of the Oil Rocks Settlement; (b) Picture of Pirallahi \& Chilov Islands

\section{DATA PROCESSING}

ENVISAT ASAR Wide Swath Medium Resolution radar satellite images were used for the purpose of oil slick detection, computation of oil spill frequencies and approximation of oil leak sources using 136 multi-temporal ENVISAT SAR images acquired during 2006-2010. The VV polarisation mode was used for the present research because of the technical suitability for the oil spill detection. The appearance of oil slicks in SAR imagery depends on the Caspian Sea conditions during the acquisition in particular the wind speeds, currents and also on the oil parameters as spill age and oil type (Ivanov et al. 2012). If the wind speed is very low then the surface might be very smooth with low level of the backscatter causing difficulties in the detection of oil spill. In case of low wind speed, it can be possible to detect thin slicks but it may be difficult to separate thick slick (Figure 3a). Low wind areas can be misinterpreted as oil slicks. If on the other hand the wind speed is too high (> 15 $\mathrm{m} / \mathrm{s}$ ) then the surface is very rough and waves are not noticeably attenuated by the oil. Also in this case, oil is hardly visible in the SAR images in a limited way. In case of high wind speed, advantage is that thick slicks can be detected whereas it can be difficult to detect thin slicks as it is shown in Figure $3 b$.
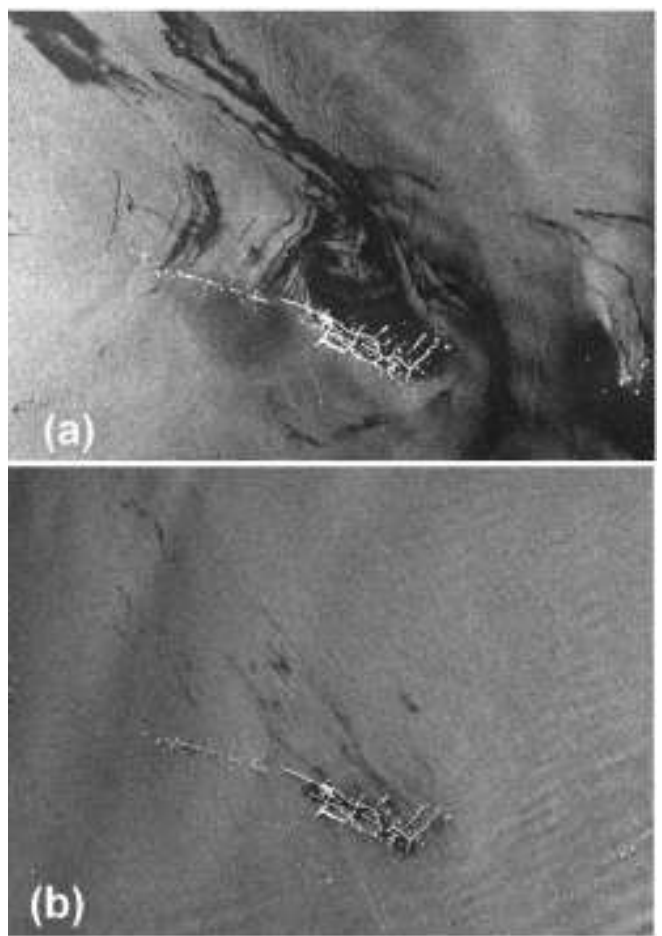

Figure 3. Identified (a) \& Non-identified (b) Oil Patterns on the ENVISAT ASAR Wide Swath Medium Resolution Images

The time-series information of wind and current speeds and their directions in the Caspian Sea corresponding to the acquisition dates of ENVISAT images were accessed through the OSCAR software (figure 4(a), (b)). OSCAR is the oil spill modelling software developed by SINTEF for deterministic and stochastic prediction of the fates and effects of oil released during an accidental release of oil, either from platforms or vessels. The models in OSCAR software account for weathering, the physical, biological and chemical processes affecting oil at sea. The wind speed and current data for the Caspian Sea were developed by Imperial College London. The wind and current data are provided at time intervals with a temporal resolution of 3 hours. The extents and count of suitable ENVISAT images for oil spill detection during 20062010 are presented in figure 5(a)-(e)) and table 1, respectively. The suitability of SAR images for oil spill detection was determined based on the visual interpretation of all acquired ENVISAT Wide Swath Medium Resolution images during 
2006-2010 and further consideration of wind and current speeds and their directions for imagery acquisition dates and time. The wind speeds of suitable 136 multi-temporal ENVISAT images 2006-2010 for oil spill detection are presented in figure 6. As it is possible to observe in figure 6 , the wind speed range is 2.5 $12.4 \mathrm{~m} / \mathrm{s}$.

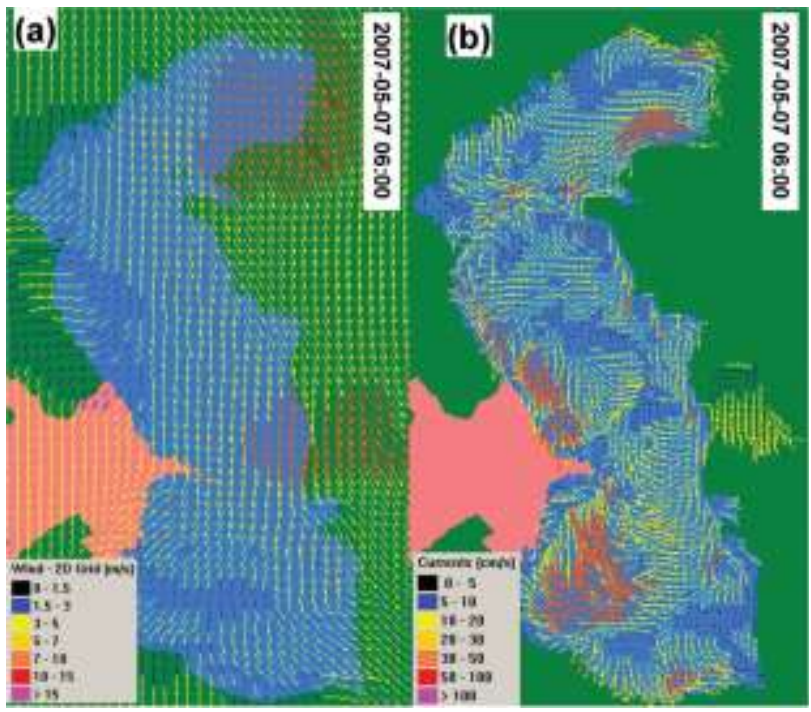

Figure 4. Example snapshots of Caspian sea winds and currents visualized in OSCAR for date and time of 2007-05-07 06:00

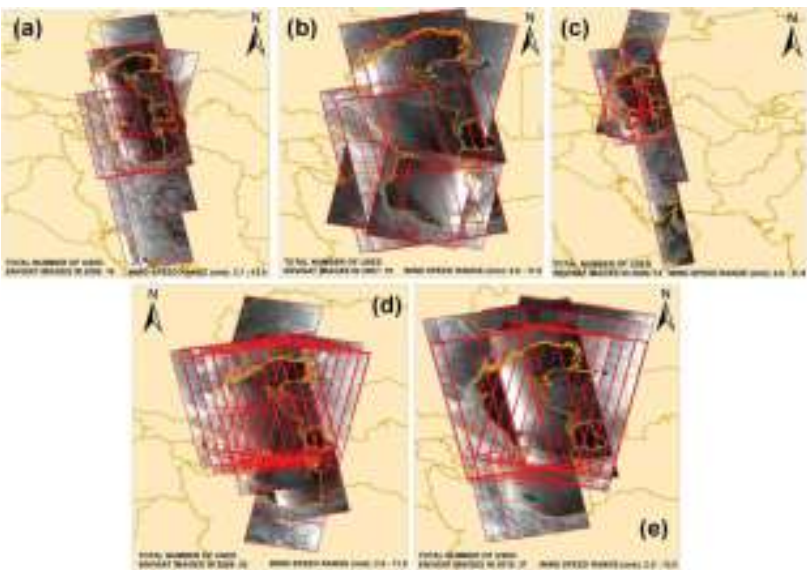

Figure 5. Extents of ENVISAT ASAR Wide Swath Medium

Resolution images suitable for oil spill detection in (a) 2006; (b) 2007; (c) 2008; (d) 2009 and (e) 2010

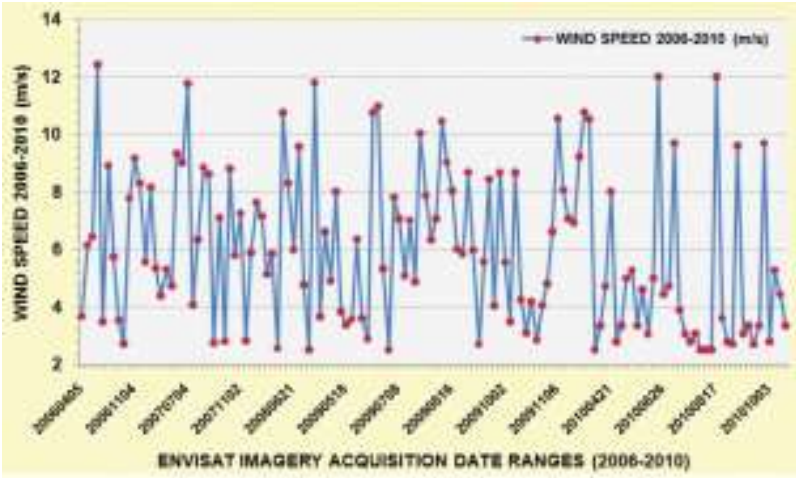

Figure 6. Wind speeds of acquired 136 multi-temporal ENVISAT images suitable for oil spill detection
The workflow used for the semi-automatic oil spill detection, visual discrimination of oil slicks from look-alikes, computation of oil spill frequencies and approximation of leak sources is presented in Figure 7. A number of automatic and semiautomatic oil spill detection algorithms were developed for the studies of environmental impacts of oil pollution in marine environment. However limited automatic oil spill detection techniques were used in this research because of the nonsignificant territorial coverage of study area and main research focus on the assessment of environmental pollution. Geocorrection of each individual ENVISAT image is performed through the geocoding relative to existing accurate geographic data of research area. This is performed for the achievement of reliable geospatial overlay analysis among detected oil spills from multi-temporal ENVISAT images. Subset of images to the extent of research area is performed to reduce the processing time of computations. Speckle filtering of the original SAR images is performed to produce better results in the process of semiautomatic detection of oil spills. The $3 \times 3$ Lee filter was applied to perform the speckle removal of ENVISAT images. The first method used for oil spill detection is an adaptive thresholding dark spots detection algorithm in the Next ESA SAR Toolbox (NEST). It first estimates the mean backscatter level in a large window, then set a threshold which is $\mathrm{k}$ decibel below the estimated mean backscatter level. Pixels with backscatter values lower than the threshold are considered as potential oil spills. Finally the detected pixels are clustered and discriminated. Only those clusters that are larger enough are considered in the detection results. The following parameters were selected to be optimum in the NEST software for the detection of oil spills around Oil Rocks Settlement, Chilov and Pirallahi Islands: Threshold shift (the detecting threshold shift in decibels lower than the local mean backscatter level) 0.01 , background window size (the window size in pixels for computing local mean backscatter) 300, minimum cluster size (the minimum cluster size in square kilometres) 0.5. Image segmentation method developed by Ruefenacht et al. (2003) in ERDAS IMAGINE software was used for the segmentation of filtered and rescaled ENVISAT images to detect oil spills. This module iteratively compares the Euclidian spectral distance between the first pixel in the image, the seed pixel, and the adjacent cells. If the Euclidian spectral distance between the two cells is less than or equal to the threshold value specified by the user, the pixel is assigned to the same region as the seed. The region is finished when there are no more cells adjacent to a member in the group that satisfy the threshold criteria. When the region is closed, the next seed pixel is selected and the process is repeated. The following image segmentation parameters were selected to be optimum for the detection of oil spills around the Oil Rocks Settlement, Chilov and Pirallahi Islands in ERDAS IMAGINE software: edge detection threshold (threshold used in edge detection) 18, edge detection minimal length (minimum acceptable length of the edge) 3 pixels, image segmentation minimal value difference (minimum value difference between neighbouring segments) 15, image segmentation variance factor (variation factor specifying how important a role that variation in pixel values within the same segment will play in determining whether to expand the segment or not) 3.5. After the preliminary detection of dark spots using adaptive thresholding and segmentation principles, visual discrimination between look-alikes and oil spills is primarily based on the consideration of following aspects for the interpretation of dark spots: shape, size, area, dB-contrast, edge type, texture, persistency and temporal repetition. Second, contextual information as wind and current speeds and directions, location of oil and gas platforms, pipelines and 
vessels are additionally considered to remove look-alikes. Third, the following Caspian Sea features are considered for the discrimination of look-alikes and oil spills: the shallow water areas along the coastal zones of the Caspian Sea using bathymetry data (figure 8), upwelling driven by coastal currents, eddies, atmospheric attenuation caused by rain, dense fog, aerosols, calm sea caused by no-wind, in-flow of river systems, etc.

The statistical or stochastic modelling of OSCAR software provides insight in how a typical oil spill scenario behaves under a wide range of weather or seasonal conditions based on the multi-year data of Caspian Sea winds and currents within OSCAR software. According to Ivanov and Vostokov et al. (2004), the approximate release of oil from the Oil Rocks Settlement is 5-15 kilograms per ton. The daily oil extraction is around 2500-3000 tons. This means that the approximate maximum daily environmental oil pollution is around 50 tons. The stochastic model of OSCAR software was used for the contamination probability prediction of oil spill around the Oil Rocks Settlement. This model was not run for Chilov and Pirallahi Islands because approximate release rates were not available. The simulation was performed for the period of one year with 576 simulations and 10 day duration of each simulation using 2006-2009 multi-year data of currents and winds. The oil type selected for the running of the model was appropriate to the Oil Rocks Settlement. The release temperature for oil was set to 108 and the water salinity $35 \mathrm{ppt}$.

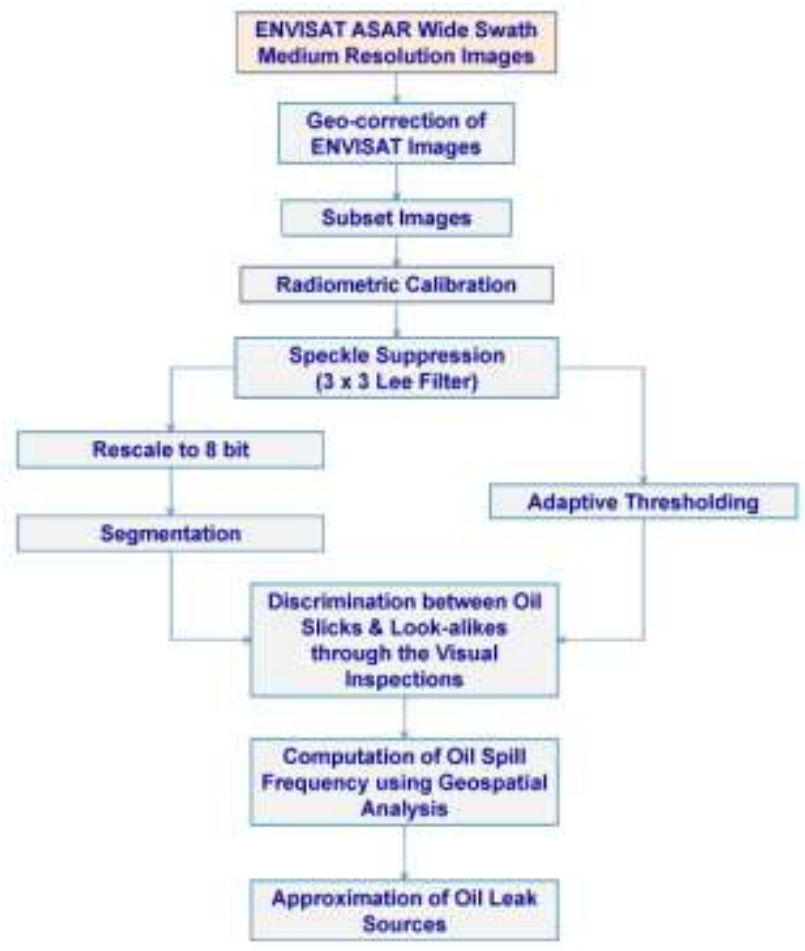

Figure 7. Workflow for the Detection of Oil Spills,

Computation of Frequencies \& Approximation of Oil Leak Sources

Geospatial overlay segmentation analysis of detected oil spills from 136 multi-temporal ENVISAT SAR images is performed to compute oil spill frequencies around the Oil Rocks Settlement, Chilov and Pirallahi Islands. It is obvious that the selected 136 ENVISAT images useful for oil spill detection are limited number of SAR images for the computation of oil spill frequencies during 2006-2010, but to the extent possible it describes the general situation with the persistence and temporal repetition of environmental pollution around the Oil Rocks Settlement, Chilov and Pirallahi Islands. The oil spill frequencies are also used for the approximation of leak sources based on the repeatability of observed oil spills at the Oil Rocks Settlement and around Chilov and Pirallahi Islands. The exponential regression analysis were performed between detected oil spill areas from 136 multi-temporal ENVISAT images and wind speeds accessed through the OSCAR software to understand the role of winds in the spatiotemporal distribution of observed oil pollution during 2006-2010. The spatiotemporal patterns of currents were also observed to understand the role of currents in the spatial distribution of oil spills around the Oil Rocks Settlement, Chilov and Pirallahi Islands.

\section{RESULTS}

The map of oil spill frequencies computed based on the 136 multi-temporal ENVISAT images suitable for oil spill detection during 2006-2010 is presented in Figure 8. The achieved oil spill frequencies and areas don't obviously cover the whole range of frequencies because these computations are explicitly based on the acquired and selected number of useful 136 multitemporal ENVISAT images for oil spill detection around Oil Rocks Settlement, Chilov and Pirallahi Islands to make the general persistence and temporal repetition assessment of regular environmental oil pollution. This approach allowed to detect hot spots with high frequencies of oil spills and their spatial distribution (Figure 8). The detection of oil spills from 136 multi-temporal ENVISAT ASAR Wide Swath Medium Resolution images and geospatial multi-temporal overlay analysis contributed to the increase of the accuracy and reliability of detected oil spills, to computation of oil spill frequencies by criticality level and determination of the hotspots of regular oil spills. The oil spill areas with no temporal repetition within 136 multi-temporal ENVISAT images and far away from the oil spill sources were not presented because of the lower reliability of regular occurrence. The approximated leak sources based on the count of oil spill frequencies assigned to rationally distributed points at Oil Rocks Settlement and around Chilov and Pirallahi Islands are presented in Figure 9. It is possible to observe that the most critical classes of oil leaks are located around the Oil Rocks Settlement. The overall achieved results provide a reliable basis for planning of cleaning activities around the Oil Rocks Settlement, Chilov and Pirallahi Islands.

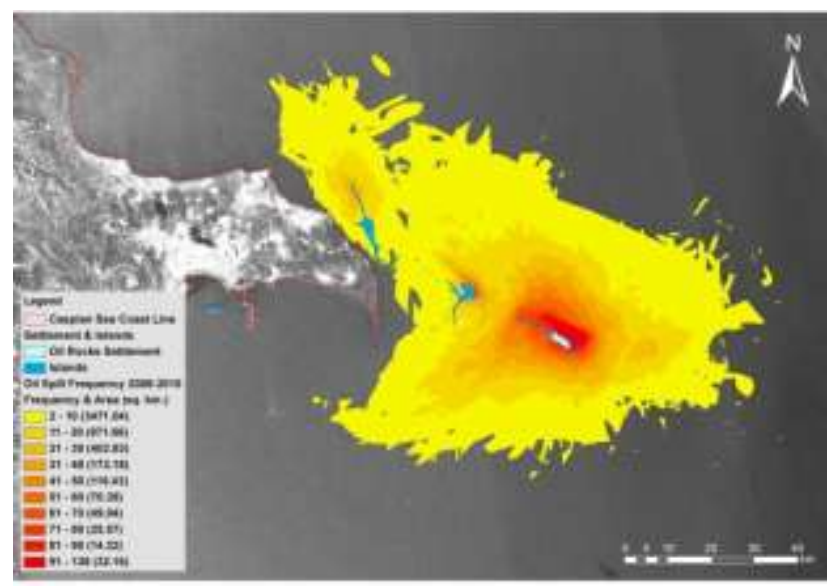

Figure. 8 Map of Oil Spill Frequency around the Oil Rocks, Chilov and Pirallahi Islands in 2006-2010 


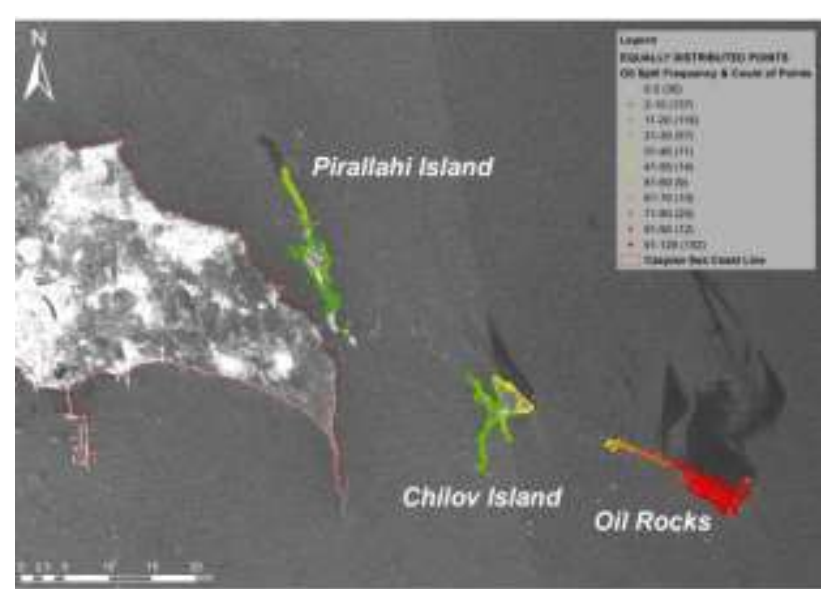

Figure 9. Map of Oil Leak Sources at Oil Rocks, Chilov and Pirallahi Islands based on the Oil Spill Frequency 2006-2010

The exponential regression analysis between wind speeds and detected oil slick areas from 136 multi-temporal ENVISAT images acquired during 2006-2010 revealed $\mathrm{R}^{2}$ equal to $63 \%$ (Figure 10). This means that wind speed is one of the most important factors controlling spatiotemporal changes of oil slick areas around the Oil Rocks Settlement, Chilov and Pirallahi Islands.

The developed Normalized Radar Cross Sections for one of the selected images with large coverage of detected oil spill equal to $1450 \mathrm{sq} \mathrm{km}$ also showed the low wind speed range of 2.5-4.5 $\mathrm{m} / \mathrm{s}$ for the low-intensity areas of oil spill on the ENVISAT image (figures 11-13).

It is well-known that winds and currents are those factors, which affect the oil slick sizes and shapes. As it is possible to observe in Figure 14, the Caspian Sea currents show the dynamic multi-directional patterns and speed which explain spatial variations of oil spills in different directions around the Oil Rocks Settlement, Chilov and Pirallahi Islands.

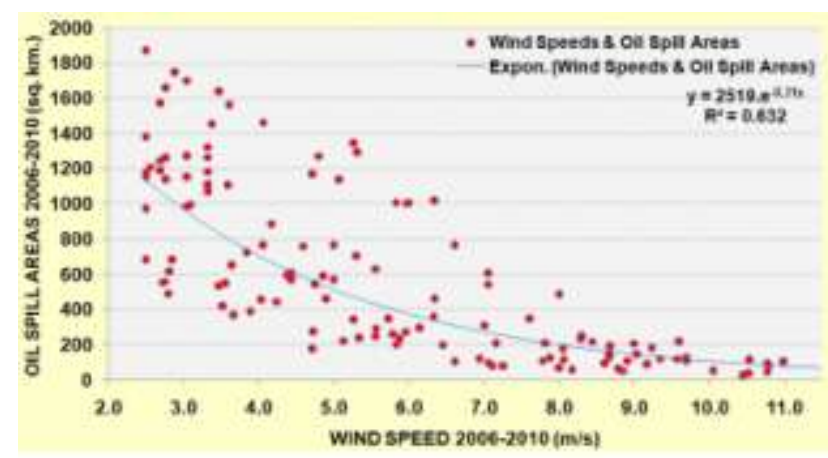

Figure 10. Exponential Regression Analysis between Wind Speeds from OSCAR Software \& Detected Oil Slick Areas from ENVISAT Images Acquired During 2006-2010

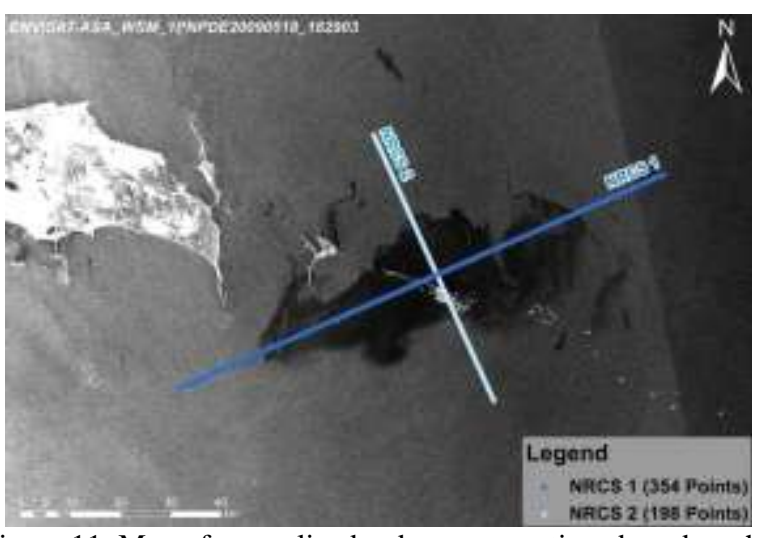

Figure 11. Map of normalized radar cross sections based on the ENVISAT radar images acquired on 18 May 2009 at 18:29.

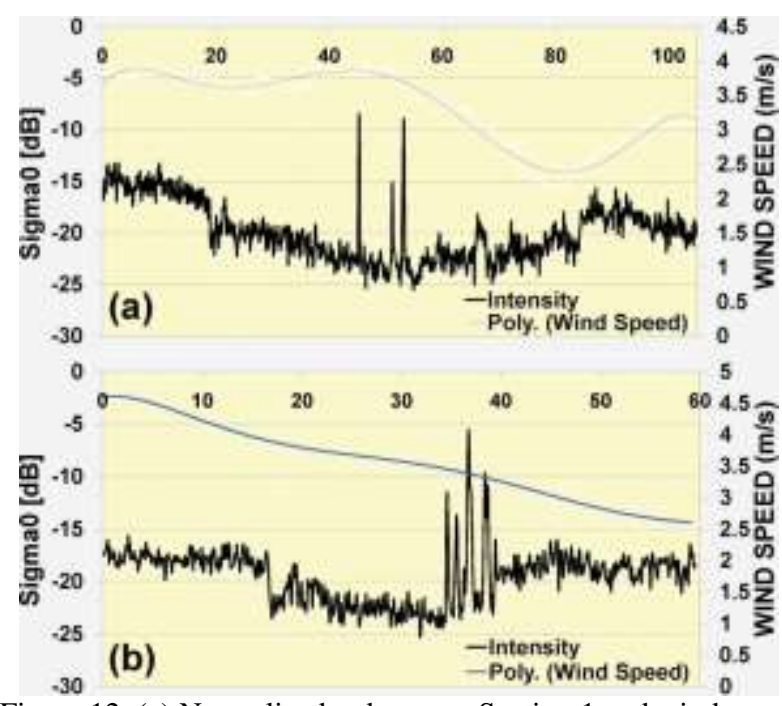

Figure 12. (a) Normalized radar cross Section 1 and wind speed (b) normalized radar cross Section 2 and wind speed.

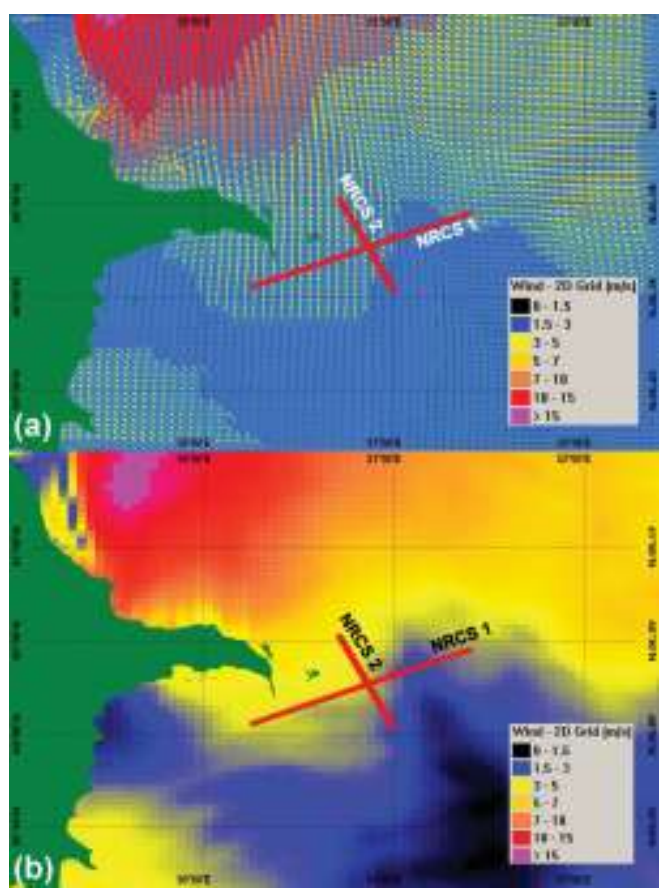

Figure 13. Wind speed from OSCAR System for 18 May 2009 at 18:29; (a) vector model and (b) grid model. 


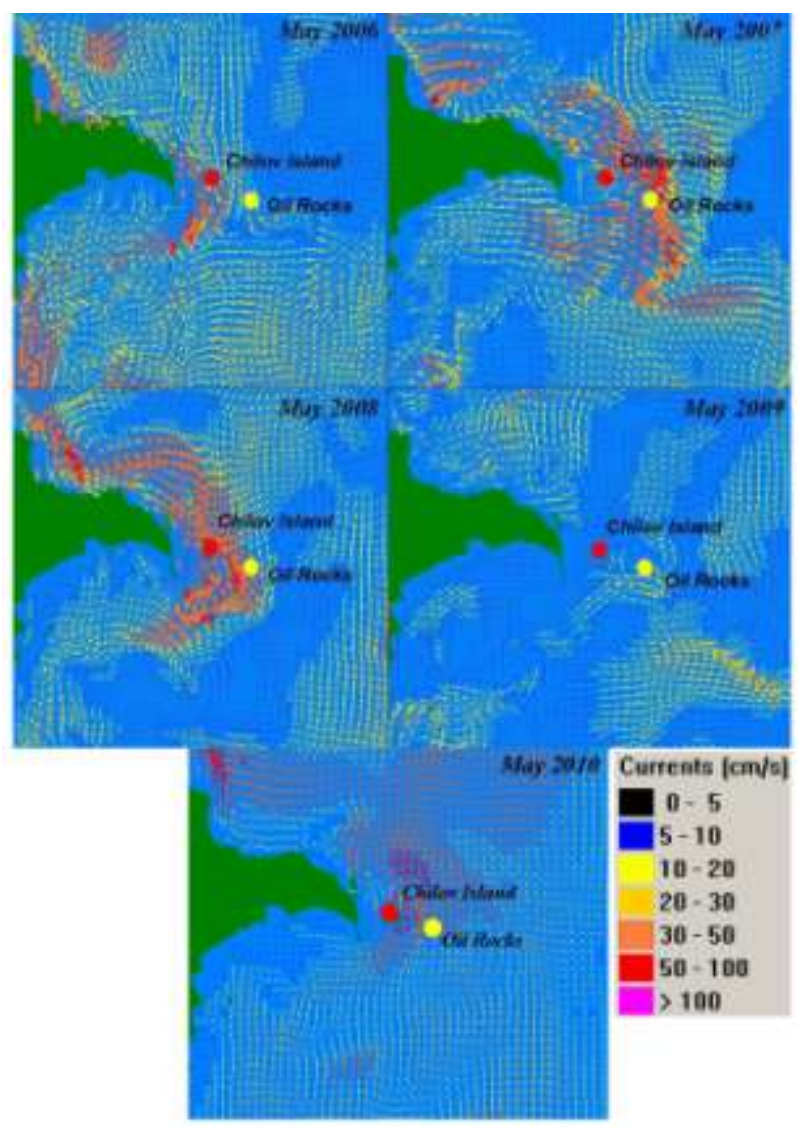

Figure 14. Caspian Sea Currents around the Oil Rocks Settlement, Chilov \& Pirallahi Islands

The stochastic oil spill modelling by the prediction of contamination probability in the OSCAR software was used for the cross-validation with the oil spill frequencies computed from detected oil spills using 136 multi-temporal ENVISAT images. As it is possible to observe in figure 15, the oil spill frequencies more than 20 were also predicted by the stochastic oil spill modelling with the contamination probability of 10 . As it was expected, high oil spill frequencies and contamination probability were growing towards the Oil Rocks Settlement. The positive trend of the regression analysis showed that the oil frequencies were increasing with higher contamination probability (figure 16). However, it was possible to observe the significant spatial variations of oil spill frequencies computed from ENVISAT images and predicted contamination probability by OSCAR software. This was also expressed in low regression coefficient equal to $30 \%$ (figure 16). These differences can be explained by the uncertainties of the input hydrodynamic and wind data in the Caspian Sea, release rates and exact location of oil leak sources. On the other hand, this can be explained by the fact that the number of acquired suitable 136 multi-temporal ENVISAT images during 2006-2010 for oil spill detection was limited to model the oil spill frequencies around the Oil Rocks Settlement, Chilov and Pirallahi Islands. Therefore, the detected oil spills based on the multi-temporal SAR images can significantly contribute to the improved prediction of oil spill distribution around the Oil Rocks Settlement, Chilov and Pirallahi Islands and vice versa the stochastic oil spill modelling can support in the determination of the inconsistency of SAR images for the assessment of oil spill frequencies.

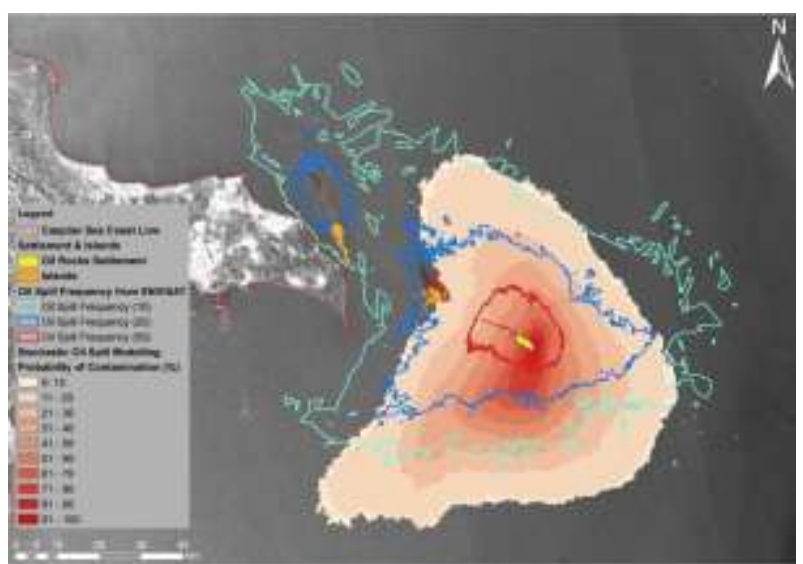

Figure 15. Oil spill frequencies and oil contamination probability around the Oil Rocks Settlement.

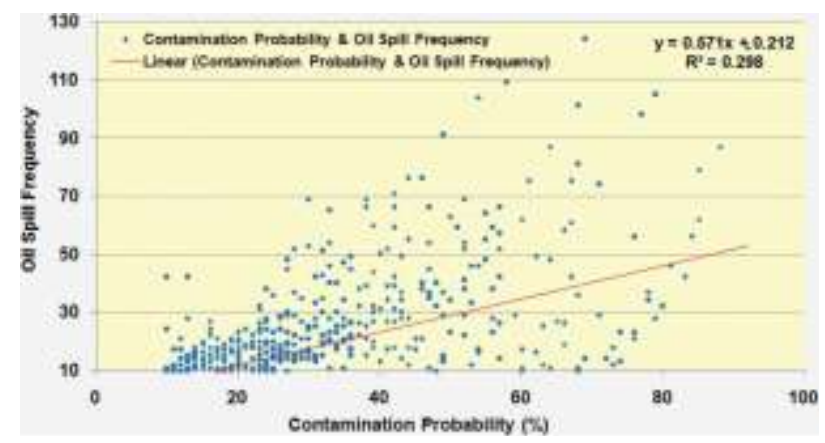

Figure 16. Linear regression analysis between contamination probability and oil spill frequencies.

\section{CONCLUSIONS}

Oil slicks were mainly detected on 136 multi-temporal ENVISAT Wide Swath Medium Resolution images acquired under the Caspian Sea wind speed range of $2.5-12.4 \mathrm{~m} / \mathrm{s}$. The following oil spill frequencies computed based on 136 multitemporal ENVISAT images were observed around the Oil Rocks Settlement, the Chilov and Pirallahi Islands during 20062010: 2-10 (3471.04 sq. km.), 11-20 (971.66 sq. km.), 21-50 (692.44 sq. km.), 51-128 (191.38 sq. km.). The persistence and temporal repetition of oil spills prove the continuous environmental pollution around the Oil Rocks Industrial Settlement, Chilov and Pirallahi Islands and provide the hot spots of oil concentration for planning of cleaning activities. It was also determined that the most critical oil leak sources were observed around the Oil Rocks Settlement with the frequency range of 41-128. The frequency ranges of 0-30 and 11-60 were observed at Pirallahi and Chilov Islands, respectively.

The exponential regression analysis between wind speeds and detected oil slick areas from 136 multi-temporal ENVISAT images for the period of 2006-2010 revealed the regression coefficient equal to $63 \%$. The regression model showed that larger oil spill areas were observed with decreasing wind speeds. The spatiotemporal patterns of currents in the Caspian Sea explained the multi-directional spatial distribution of oil spills around the Oil Rocks Industrial Settlement, Chilov and Pirallahi Islands.

The positive trend of the regression analysis showed that the oil spill frequencies computed from 136 multi-temporal ENVISAT images were increasing with higher contamination 
probability predicted by OSCAR software. The linear regression analysis between detected oil spill frequencies from ENVISAT images and stochastic contamination probability predicted by OSCAR oil spill modeling software showed the positive trend with the regression coefficient of $30 \%$. However, it was possible to observe the significant spatial variations of oil spill frequencies computed from ENVISAT images and predicted contamination probability by OSCAR software. These differences can be explained by the uncertainties of the input hydrodynamic and wind data in the Caspian Sea, release rates and exact location of oil leak sources. On the other hand, this can be explained by the fact that the number of acquired suitable ENVISAT images during 2006-2010 for oil spill detection was limited to model the oil spill frequencies around the Oil Rocks Settlement, Chilov and Pirallahi Islands. Therefore, the detected oil spills based on the multi-temporal SAR images can significantly contribute to the improved prediction of oil spill distribution around the Oil Rocks Settlement, Chilov and Pirallahi Islands and vice versa the stochastic oil spill modelling can support in the determination of the inconsistency of the SAR images for the detection of oil spill frequencies and approximation of leak sources.

\section{ACKNOWLEDGEMENTS}

We would like to acknowledge European Space Agency (ESA) for the provision of access to ENVISAT images under the project ID: 15837.

\section{REFERENCES}

Akar, S., Lutfi Süzen, M., Kaymakci, N., 2011. Detection and object-based classification of offshore oil slicks using ENVISAT-ASAR images. Environmental Monitoring and Assessment, 183, pp. 409-423

Brekke, C. \& Solberg, A. H. S., 2005. Oil spill detection by satellite remote sensing. Remote Sensing of Environment, 95, pp. 1-13.

Del Frate, F., Petrocchi, A., Lichtenegger, J. \& Calabresi, G., 2000. Neural networks for oil spill detection using ERS-SAR data. IEEE Transactions on Geoscience and Remote Sensing, 5, pp. 2282-2287.

Espedal, H. A., 1998. Detection of oil spill and natural film in the marine environment by spaceborne synthetic aperture radar. $\mathrm{PhD}$ thesis, Department of Physics University of Bergen and Nansen Environment and Remote Sensing Center, Norway.

Espedal, H. A., \& Wahl, T., 1999. Satellite SAR oil spill detection using wind history information. International Journal of Remote Sensing, 20(1), pp. 49-65.

Gade, M., Scholz, J., \& von Viebahn, C., 2000. On the detectability ofmarine oil pollution in European marginal waters by means of ERSSAR imagery. Proc. IGARSS 2000, 6, pp. $2510-2512$.

Girard-Ardhuin, F., Mercier, G., \& Garello, R., 2003. Oil slick detection by SAR imagery: Potential and limitation. In Proc. OCEANS 2003, 1, pp. 164-169.
Ivanov, A. Y., Vostokov, S. V., Ermoshkin, I. S., 2004. Mapping oil films on the sea surface using synthetic aperture radar images (the Caspian Sea as an example) [in Russian]. Earth Observation Space, 4, pp. 82-92.

Karantzalos, K., \& Argialas, D., 2008. Automatic detection and tracking of oil spills in SAR imagery with level set segmentation. International Journal of Remote Sensing, 29(21), pp. 6281-6296.

Kotova, L. A., Espedal, H. A., \& Johannessen, O. M., 1998. Oil spill detection using spaceborne SAR; a brief review. Proc. 27th ISRSE, Tromsb, Norway.

Martinez, A. \& Moreno, V., 1996. An oil spill monitoring system based on SAR images. Spill Science and Technology Bulletin, 1-2, pp. 65-71.

Ziemke, T., 1996. Radar image segmentation using recurrent artificial neural networks. Pattern Recognition Letters, 4, pp. 319-334.

Kubat, M., Holte, R. C. \& Matwın, S., 1998. Machine learning for the detection of oil spills in satellite radar images. Machine Learning, 2-3, pp. 195-215.

O’Brein, G. W., Lawrence, G. M., Williams, A. K., Glenn, K., Barrett, A. G., Lech, M., et al., 2005. Yampi Shelf, Browse Basin, North-West Shelf, Australia: A test-bed for constraining hydrocarbon migration and seepage rates using combinations of 2D and 3D seismic data and multiple, independent remote sensing technologies. Marine and Petroleum Geology, 22, pp. 517-549.

Ruefenacht, B, Vanderzanden, D, Morrison, M., 2003. New technique for segmenting images. Utah: USDA Forest Service Remote Sensing Applications Center.

Solberg, A. H. S., Storvik, G., Solberg, R., \& Volden, E., 1999. Automatic detection of oil spills in ERS SAR images. IEEE Transactions on Geoscience and Remote Sensing, 37(4), pp. 1916- 1924.

Topouzelis, K. N., 2008. Oil spill detection by SAR images: Dark formation detection, feature extraction and classification algorithms. Sensors, 8, pp. 6642-6659.

Topouzelis, K., Karathanassi, V., Pavlakis, P. \& Rokos, D., 2002. Oil spill detection:SAR multi-scale segmentation and object features evaluation. In 9th International Symposium on Remote Sensing (SPIE), pp. 77-87.

Topouzelis, K., Muellenhoff, O., Ferraro, G. and Tarchi, D., 2007. Satellite Mapping Of Oil Spills In The East Mediterranean Sea, Proceedings of the 10th International Conference on Environmental Science and Technology, Kos Island, Greece

Ivanov A. Yu., Dostovalov M. Yu., Sineva A. A., 2012. Characterization of oil pollution around the oil rocks production site in the Caspian Sea using spaceborne polarimetric SAR imagery. Izvestiya, Atmospheric and Oceanic Physics, 48(9), pp. 1014-1026 